\title{
The Role of Knowledge Mapping in Electronic Government
}

\author{
Meliha Handzic \\ School of Information Systems, Technology and Management \\ The University of New South Wales, Sydney 2052, Australia \\ m.handzic@unsw.edu.au
}

\begin{abstract}
This paper explores the role of knowledge mapping in electronic government. It begins by outlining the rationale for knowledge mapping. It then reviews different conceptualisations of knowledge maps. These include concept, competency and process based maps. Then, it illustrates the application of these maps in a series of examples from the Australian government websites. The paper concludes by identifying some major issues and challenges for the future of knowledge mapping in electronic government.
\end{abstract}

\section{Introduction}

According to some analysts, the capacity of digital storage in the last decade has increased worldwide at twice the rate predicted for the growth of computing power [5]. The gap between the two trends represents an interesting pattern in the state of evolution. Our ability to capture and store data has far outpaced our ability to process and utilise it. In electronic government, the proliferation of knowledge artefacts on websites creates an overload that is threatening to inhibit the efficient functioning of these institutions. As more documents are added on the web it becomes clear that there needs to be some sort of mechanism to help organise and search for useful knowledge. Otherwise it may remain invisible and unused. This poses a major challenge for knowledge management (KM).

Some authors point to "knowledge mapping" as a feasible KM method to coordinate, simplify, highlight and navigate through complex webs of knowledge possessed by institutions [20]. Knowledge maps or k-maps point to knowledge but they do not contain it . They are guides, not repositories [2]. One of the main purposes of k-maps is to locate important knowledge in an organisation and show users where to find it [12]. Effective k-maps should point not only to people but to document and databases as well. K-maps should also locate actionable information, identify domain experts, and facilitate organisation-wide learning [4]. They should also trace the acquisition and loss of knowledge, as well as map knowledge flows throughout the organisation [7].

Knowledge mapping can offer many benefits including economic, cultural, structural and knowledge returns [20]. Indeed, empirical findings indicate that knowledge mapping has been successfully used in education to facilitate students' learning [1]. 
Knowledge mapping tools have also been used in medical field and aerospace industry [3],[6]. However, despite its many possible beneficial applications in industry, a recent survey shows that knowledge mapping is a relatively rarely used knowledge management method in business organisations [15].

The purpose of this paper is to explore this issue in the government sector. In particular, our objective is to examine whether and how knowledge mapping is used to facilitate the visibility of and access to government knowledge resources required by its citizens. Multiple cases from Australian Government will be analysed to illustrate the level of use and benefits achievable from different knowledge mapping applications.

\section{Overview of Knowledge Maps}

A review of literature reveals a variety of definitions and categories of knowledge maps proposed and used by industry and academia. Most definitions circle around the idea of tools or processes that help users navigate the silos of artefacts that reside in an organisation, while determining meaningful relationships between knowledge domains [7], [14], [20]. For the purpose of this paper, knowledge map or k-map is understood as the visual display of knowledge and relationships using text, stories, graphics, models or numbers [4], [18], [19].

K-map examples provided by Eppler [4] include knowledge application, knowledge structure, knowledge source, knowledge asset and knowledge development maps. Wexler [20] identifies concept, competency, strategy, causal and cognitive maps. Plumley [13] suggests that knowledge maps can be procedural, concept, competency and social network maps. A more abstract set of categories focusing primarily on cognitive maps is used by Huff [11]. The analysis of similarities and differences among these various types demonstrates that some classifications are simply different ways of referring to essentially the same maps.

From this analysis, a three-class categorisation of k-maps was adopted in this paper, based on their prime function. In short, concept maps answer the "what" knowledge question by structuring the phenomenon in terms of its basic elements and relationships; competency maps answer the "where/who" question by pointing to sources of expertise; while process maps answer the question of "how" by visualising the necessary steps in a business process or situation. In practice, most maps will be a combination of one or more basic types in a single image.

\subsection{Concept Based K-maps}

The group of concept based k-maps or taxonomies includes conceptual k-maps [14] and knowledge structure maps [4], as both these maps provide a framework for capturing and organising domain knowledge of an organisation around topical areas. They represent a method of structuring and classifying content in hierarchical manner. Concept based maps also allow for internal experts' knowledge to be made explicit in a visual, graphical representation that can be easily understood and shared. Mind maps, as special forms of concept or cognitive maps [20], provide further ability to 
express and organise a person's thoughts about a given topic, for example, the author's own understanding of the knowledge management phenomena shown in Figure 1[9].

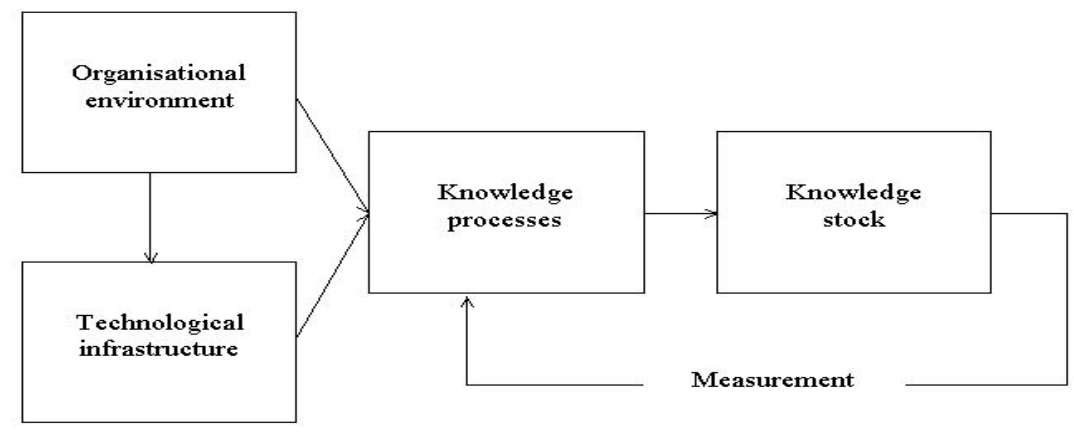

Fig. 1. Knowledge Management Ontology

Concept maps improve both the visibility and usability of organisational knowledge. The visibility is typically enhanced by the structure of the concept maps and the use of the visual symbols. The visual symbols can be quickly and easily recognised, while the minimum use of text makes it easy to scan for a particular word or phrase. In short, visual representation allows for development of a more holistic understanding of the domain, that words alone cannot convey. Concept maps also improve the usability of knowledge as they organise knowledge artefacts around topics rather than functions. Thus, they provide the ability to cross functional boundaries.

\subsection{Competency Based K-maps}

Competency based k-maps cover a group of similar maps including competency kmaps [13], knowledge source and knowledge assets maps [4]. They all provide an overview of expertise that resides in the organisation along with the identification of entities who posses such expertise. They act as "yellow pages" or directories which enable people to find needed expertise. They visually qualify the existing stock of knowledge of an individual, team or whole organisation. They can document the skills, positions and career paths. Essentially, they are simple graphic balance sheets of a company's intellectual capital [4].

One of the major benefits of competency based k-maps is that they make the human capital of the organisation highly visible. They can be used to profile a company's workforce across a number of criteria such as domains of expertise, proximity, seniority or regional distribution. For example, Figure 2 shows experts (ie. darker 
nodes) network with nodes representing different experts and paths representing the strength of their bonds [17].

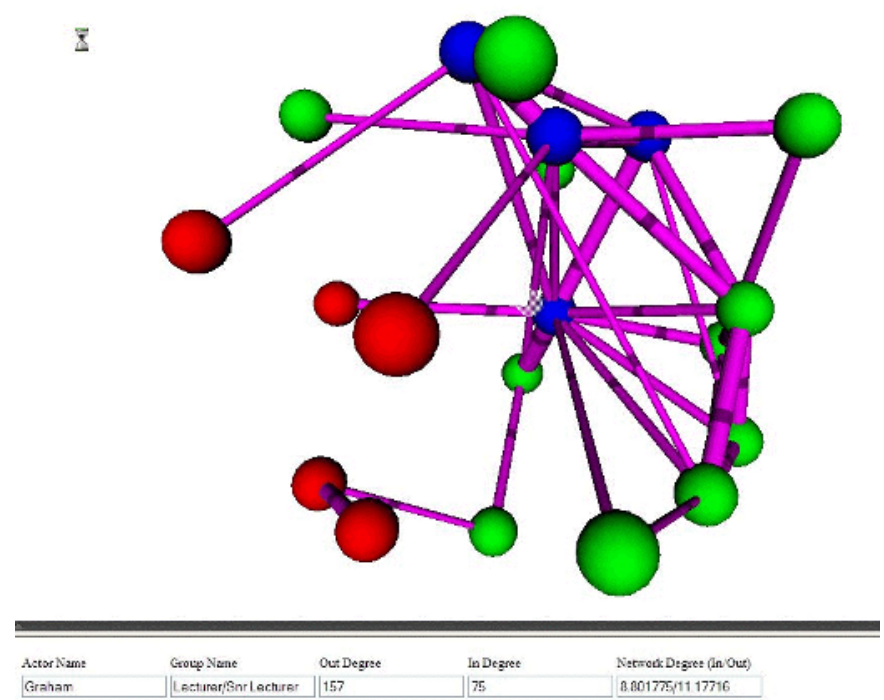

Fig. 2. Expert Network Map

Alternatively maps can be used to depict the stages to develop a certain competence. This can be used to help project managers in assessing the available knowledge for projects and jobs, as well as to make decisions about personal development and training [4]. Competency based maps can also greatly improve the usability of intellectual capital within the organisation. When converted into "yellow pages" and directories these maps can enable employees to easily find needed expertise within an organisation [13].

\subsection{Process Based K-maps}

Process based k-maps are one of the most commonly used types of knowledge maps in organisations. They include procedural maps [13] and knowledge application maps [4], as they are similar in that they both focus on work/business processes. Essentially, process based k-maps present business processes with related knowledge sources in auditing, consulting, research and product development. Any type of knowledge that drives these processes or results from execution of these processes can be mapped. For example, this could include tacit knowledge in people, explicit knowledge in databases, customer or process knowledge [13].

Process k-maps have several benefits. They help to improve the visibility of knowledge in organisation by showing which type of knowledge has to be applied at a certain process stage or in a specific business situation. On top of this, these maps also provide pointers to locate that specific knowledge [4]. 


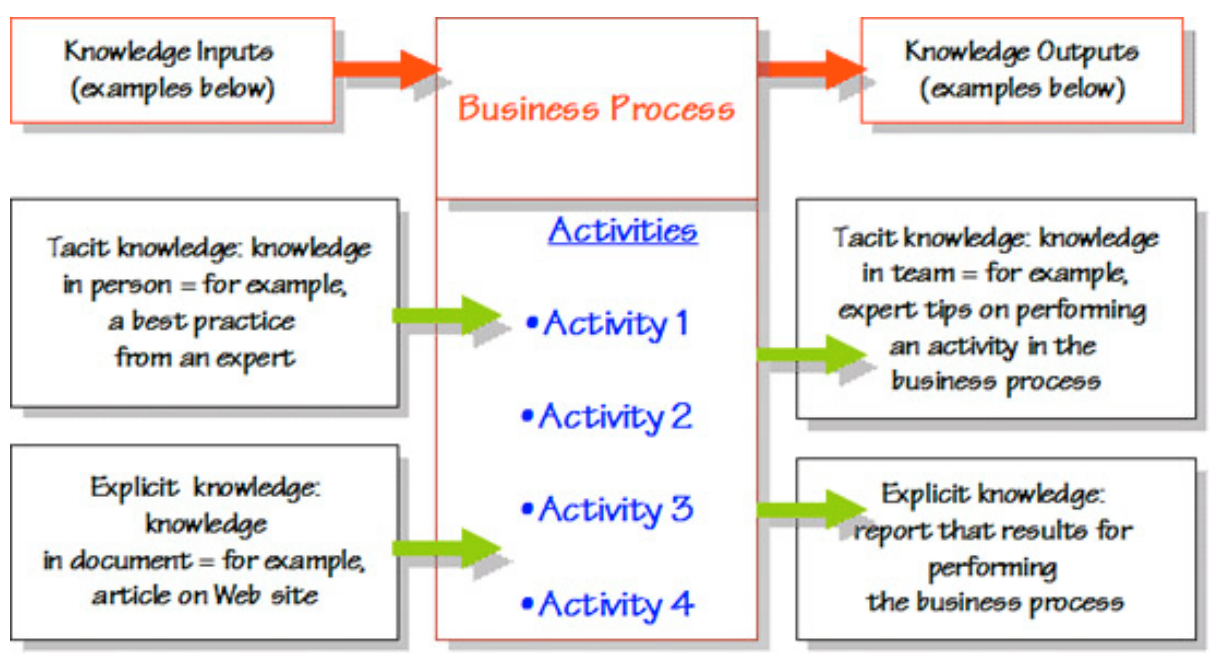

Fig. 3. Process-based Map

Process based k-maps also help to improve the usability of knowledge in an organisation by forcing participants to identify key knowledge areas that are critical to their business. The analysis of the knowledge map generates ideas for sharing and leveraging knowledge most suited to the organisation and the business context. Finally, the clear and simple visual format is easy to update and evolve over time [13].

\section{K-map Application Cases}

So far, Australian federal agencies have been successful in implementing an initial "Government Online" strategy which ensured that by 2001 all appropriate information and services were available via the internet for those wanting to access them [8]. According to Stephens [16], the growth of online service delivery creates new opportunities, capabilities and expectations. "Better Service, Better Government" is a strategy that maps out the next phase in the federal government's drive to move on from placing information and services on-line. Key objectives include greater efficiency, convenient access to services, better service delivery, integration of related services, building of user trust and confidence, and enhanced citizen engagements or "edemocracy".

Knowledge needs to be managed to serve the objective of effective online service delivery. This forces new approaches to knowledge management. However, a stocktake of most notable knowledge management activities in the Australian Public Sector (APS) reveals that very few agencies have incorporated knowledge management into their big picture [16]. The following examples show how some of these agencies applied "knowledge mapping" as a way to increase visibility and usability of their knowledge resources. 


\subsection{Case One: Australian Bureau of Statistics}

Collections of digital content represent an exciting development full of promise for users for research, education and practice purposes. Digital collections include all kinds of electronic material including full-text documents, still and moving images, music, maps, archival manuscripts, geographic and satellite data. Issues of selection, digitisation, organisation and accessibility to these collections are all of equal importance [10]. Concept maps provide a valuable framework for organising digital content around subject areas. They also serve as subject gateways. As an example, this paper examines the website of the Australian Bureau of Statistics (ABS), Australia's official statistical organisation http://www.abs.gov.au.

ABS assists and encourages informed decision-making, research and discussion within governments and the community, by providing a high quality, objective and responsive national statistical service. For organising its statistical products, ABS uses a "home-grown" classification scheme. The broad themes include: economy, environment \& energy, industry, people and regional statistics. Each of these is further divided into more specific categories. For example, industry theme includes agriculture and rural, building and construction, information technology, manufacturing, mining, retail, science \& innovation, service industries, tourism and transport statistics. At the next level are related data and publications. In this way, the concept map outlines the global architecture of a knowledge domain of ABS. By dividing its statistical expertise into logical blocks, ABS helps the user in finding, comprehending and interpreting it.

\subsection{Case Two: Australian Government Entry Point}

The following example examines the application of the competency map in the context of e-government. As mentioned earlier, competency k-maps act primarily as "yellow pages" or directories, which enable people to find needed expertise. The Australian Government Entry Point http://www.fed.gov.au serves this purpose by currently signposting over 700 relevant Australian Government web sites and over 1 million pages of text for knowledge seekers.

It is the Australian Government's aim to provide equitable access to its expertise, and the variety of access approaches available on this site allow users to choose the method that best suits their needs. Customised links are provided for different types of users including individuals, students, businesses and non-residents. For example, the site points to relevant places where best advice on benefits and payments may be obtained for individuals, education related information for students, taxation help for businesses, and immigration tips for non-residents. The site has been developed with useability and accessibility principles as the main drivers for design. The incorporation of a common look and feel across the site with user needs and feedback providing guidance on specific features has resulted in a user-centred design. The site has been designed to keep navigation around the site as simple as possible.

The site is mainly text-based. The home page has been designed to help users find the expertise needed quickly and easily. The goal of this page is to present as much relevant information as possible without overwhelming the user. Good design practice 
has been incorporated by striking a balance between keeping the site visually interesting and structuring it so that the layout of pages is logical and accessible. A number of different browsers and versions of browsers are supported to increase the useability of the site. User privacy is maintained at all times. By dividing the government competences into major areas of expertise, and linking users to places where this expertise resides, the map provides much needed assistance to specialised communities of users.

\subsection{Case Three: Business Entry Point}

A great deal of knowledge is required in order to set up a small business including government requirements, licences and permits, registering the business and reporting requirements, employees' rights and obligations, financial assistance, taxation matters, closing and selling a business [10]. The procedural k-map can be a valuable tool for the prospective businessman by showing the person which steps have to be executed and what knowledge is required at each step of the process. Much of this information can be found from the Australian Business Entry Point (BEP) website http://www.business.gov.au.

The BEP is a major online government resource for the Australian business community. It provides business with a wide range of services and information about start-up, taxation, licensing and legislation, as well as significant transactions such as taxation compliance and licence applications. For example, the "Starting a business" page provides an overview of what is needed to be done in each state when starting up a business. It describes all necessary steps to be taken and supplies connections with relevant knowledge sources. By providing this particular process based k-map, the BEP enables businesses to comply with government requirements more simply and conveniently.

\section{Issues and Challenges}

All maps have advantages and disadvantages. Thus, one of the major challenges facing map makers is to gather the right reference knowledge in a framework that everyone can relate to [4]. This requires continuous user involvement in a participative and interactive manner [18], [19], [20]. There is also the risk of information overload or underload if the map represents too many or too little elements [4]. Other challenges faced by map makers include the reduction of complex structures to graphic symbols, the risk that the commitment to one scheme will lead to the neglect of other perspectives, the danger of using an outdated map, the potential harmful effects if the map is seen by unauthorised users [4].

There is a widespread agreement among academics and practitioners that successful knowledge mapping requires careful planning and implementation, so that the many dangers of making and using low quality maps mentioned above can be avoided. The following guidelines outline a series of critical steps claimed to yield best results [19], [7], [4]. In the planning stage, these are: find a sponsor, determine 
the rational and scope, begin awareness building process, identify stakeholders, decide upon the technical requirements, and assign a custodian of the map. In the creation stage the key activities include: collect the information about knowledge needs, hold workshops for users, keep in mind factors that contribute towards an effective k-map, and finally create the map.

Finally, in the implementation stage, a review is suggested of the completed map in terms of four quality criteria: functional, cognitive, technical and aesthetic [4]. Functional quality is evaluated in terms of how well the map serves its purpose, and whether there are an update process and feedback mechanism for improvement. Cognitive quality is evaluated in terms of adequate information load, levels of details, and comparable and discernible elements. Technical quality requires good access time, legibility on various screen resolutions and interfaces, and security from unauthorised access. Finally, aesthetic quality includes scalability and pleasing visual impression through the adequate use of colour and geometry. It is suggested that by meeting these criteria well, k-mapping could become the "killer" KM application in business (and government).

Currently, there are no empirical studies available to reliably inform about the extent to which these guidelines were followed by the government agencies in producing k-maps presented in this paper, or to show if and to what extent the expected benefits have been achieved. Future research is necessary to answer these questions. In the author's personal opinion, the sample k-maps score fairly well on all four criteria for quality k-maps. They have been designed to serve particular purposes (functional quality) and provide feedback mechanisms for users to suggest improvements. They are also able to be grasped in one glance, while providing the ability to offer various levels of detail (cognitive quality) in a visually pleasing and scalable manner (aesthetic quality). Finally all maps are iterative and flexible so that they promote continuous change, updating and improvement [20] in consultation with map users.

\section{Conclusions}

The aim of this paper was to provide a better understanding of the role of knowledge mapping in electronic government. From what we have learned so far from the literature and cases reviewed, concept maps help improve the visibility of knowledge in government by allowing citizens to access the relevant domain topics and ideas more quickly. Competency maps converted into yellow pages and directories help citizens find needed expertise, while process maps provide guidance to citizens involved in task execution by showing them which type of knowledge has to be applied at a certain process stage and by pointing to its source. Clearly, the benefits of implementing knowledge maps in e-government can be far reaching. It is hoped that with an improved understanding of the concepts and clear guidelines for development of quality knowledge maps, governments will be able to fully realise these benefits. 


\section{References}

1. Chung G., Osmundson E., Herl H. and Klein D. (1999), "Knowledge Mapping in the Classroom, A tool for examining the development of a student's conceptual understanding", CSE Technical Repot 507, UNSW, August 1999.

2. Davenport T.H. and Prusak L.(1998), Working knowledge: How organisations manage what they know, Harvard Business School Press, Boston.

3. Depres C. and Chauvel D. (1999), "Knowledge Management(s)", Journal of Knowledge Management, 3(2), pp.110-120.

4. Eppler M. (2003), "Making Knowledge Visible through Knowledge Maps: Concepts, Elements, Cases", in Holsapple C.W. (ed), Handbook on Knowledge Management, Vol 1, Springer-Verlag, Berlin, pp 189-205.

5. Fayyad U. and Uthurusamy R. (2002), "Evolving Into Data Mining Solutions for Insight", Communications of the ACM, Vol 45, No 8. August, pp.28-31.

6. Gordon, J. (2000), "Creating Knowledge Maps by Exploiting Dependent Relationships", Knowledge Based Systems, 13, pp. 71-79.

7. Grey, D. (1999), "Knowledge Mapping: A Practical overview", URL: http://www.smithweaversmith.com/knowledg2.htm

8. Handzic, M. (2003), "Empowering Society through Knowledge Records", in Wimmer M.A. (ed) Proceedings of IFIP International Working Conference Knowledge Management in Electronic Government (KMGov 2003), Rhodes, May 26-28, pp. 262-267.

9. Handzic M. and Hasan H. (2003) "The Search for an Integrated KM Framework", chapter 1 in Australian Studies in Knowledge Management, UOW Press, Wollongong, pp. 3-34.

10. Henninger M. (2003) The Hidden Web, UNSW Press, Sydney.

11. Huff A. (ed) (1990), Mapping Strategic Thought, Wiley, NY.

12. Kim S., Suh E. and Hwang H. (2003), Building the Knowledge Map: An Industrial case study, Journal of Knowledge Management, vol 7, no 2, pp. 34-45.

13. Plumley D. (2003), "Process-based knowledge mapping: A practical approach to prioritising knowledge in terms of its relevance to a business or KM objective" Knowledge Management Magazine, March 03. http://www.destinationkm.com/articles

14. Speel P.H., Shadbolt N., deVries W., vanDam P.H. and O'Hara K. (1999), “Knowledge mapping for Industrial purposes" Proceedings of the $12^{\text {th }}$ Workshop on Knowledge Acquisition (KAW'99), Alberta, 16-21 October. http://sern.ucalgary.ca/KSI/KAW/KAW99/papers/Speel1

15. Stanford X, (2001), "Who's mapping” Knowmap, 1(4).

16. Stephens D. (2001), "Knowledge Management in the APS: A Stocktake and a Prospectus", Canberra Bulletin of Public Administration, No. 100, June, pp.26-30.

17. Stephens, G. and Handzic, M. (2004), "Knowledge Discovery Through Visualising Using Virtual Reality", Proceedings of the Thirty-Seventh Annual Hawaii International Conference on System Sciences -HICSS37 (CD/ROM), January 5-8, 2004, Computer Society Press, Ten Pages.

18. Vail E. (1999a), "Mapping Organisational Knowledge", Knowledge Management Review, 8, May/June, pp.10-15.

19. Vail E. (1999b), "Knowledge Mapping: Getting started with knowledge management", Information Systems Management, 16(4), pp. 16-23.

20. Wexler M.(2001), "The who,what, why of knowledge mapping”, Journal of Knowledge Management, 5(3), pp. 249-263. 